Joachim Perels

\title{
Der Umgang mit Tätern und Widerstandskämpfern nach $1945^{*}$
}

\author{
I. Abwehr der »Todesfuge "
}

Auf Gedichte Paul Celans reagieren Feuilletons der frühen Bundesrepublik oftmals abwehrend. 1945 schrieb Celan - er hatte zwei nationalsozialistische Arbeitslager überlebt - das außerordentliche, mittlerweile fast zu bekannt gewordene Gedicht »Todesfuge«. In ihm heißt es: »Ein Mann ... pfeift seine Juden hervor läßt schaufeln ein Grab in der Erde ... der Tod ist ein Meister aus Deutschland ... er hetzt seine Rüden auf uns und schenkt uns ein Grab in der Luft. «' Für dieses Gedicht wählte der Literaturkritiker Günther Blöcker im Berliner »Tagesspiegel « vom I I. Oktober I 959 die Charakterisierung: "Kontrapunktische Exerzitien auf dem Notenpapier «" - ein Vergleich, der die Mordvorgänge, die Celan in Worte faßt, schlecht ästhetisierend beiseite schiebt, auf ein Notenpapier verbannt. Auf diese Abwehr der Wahrnehmung des Grauens, die Celan im Innersten traf, antwortete er wenige Tage später mit dem Gedicht "Wolfsbohne ${ }^{3}$ Es findet sich in seinem Nachlaß. Celan ruft seine Eltern als Zeugen gegen ein vom Gehalt abstrahierendes Verständnis der »Todesfuge « an. Am Beginn heißt es in einer Zeile: "Weit, in Michailowka, in Gaissin, in der Ukraine, wo sie mir Vater und Mutter erschlugen." Celan adressiert das Gedicht an seine Mutter. Es zeigt, wie die Abwehr der Erinnerung die Toten gleichsam ein zweites Mal auslöscht. Celan schreibt: »Gestern kam einer von ihnen und tötete Dich zum anderen Mal.«Celan fährt fort: »Du, die Du Wolfsbohne sagtest, sie, die die Wolfsschanze bauten. - Wer lebt? « Die Frage ist hart: Leben die, die den Führerbunker bauten, in dem Stauffenberg den Diktator auszuschalten suchte, weiter? Welche Bedeutung hat es, daß sich nach einer Umfrage Mitte der soer Jahre fast die Hälfte der Bevölkerung dagegen ausspricht, eine Schule nach Stauffenberg zu nennen? Celan gibt in dem Gedicht eine zugespitzte Antwort: »Mutter, keiner fällt den Mördern ins Wort.«

\section{Stellung des Widerstands und der Emigration zu Staatsverbrechen}

Zur Verdrängung des Systems des Schreckens existierte vor allem auf rechtlichem Gebiet eine Alternative. Die Ahndung der Staatsverbrechen der Trägerschichten des Dritten Reiches - die schwerste Erblast, mit der die Bundesrepublik über Jahrzehnte konfrontiert wird - ist von führenden Juristen des deutschen Widerstands und der Emigration im Kern in gleicher Weise konzipiert worden. Ihre Sichtweise wurde mit manchen Erweiterungen und Veränderungen in der Gesetzgebung der Alliierten und ihrer Nachkriegsjudikatur im bestimmten Maße aufgenommen. In einem von Paulus

* Vortrag in der Staatsbiblıothek Berlın am 19.7. 1997 auf Einladung der Gedenkstatte Deutscher Widerstand. Der Vortrag wurde Jeicht uberarbeitet.

I P. Celan, Todesfuge (1945), in: K. Wagenbach (Hrsg.), Lesebuch. Deutsche Literatur zwischen 1945 und 1959, Berlin 1980, S. 29

2 Vgl. P. Celan, Die Gedichte aus dem Nachlaß, hrsg. v. B. Badiou, J.-C. Rambach u. B. Wiedemann, Frankfurt/M. 1997, S. 359 .

3 Ebd., S. $306 \mathrm{ff}$

4 J.Perels, Wider die `Normalısierung des Nationalsozialismus, Hannover 1996, S. 74 m.w.Nachw. 
van Husen im Juni und Juli 1943 verfaßten Text des Kreisauer Kreises wird die grundsätzliche Position markiert, die »Rechtsschändung des Regimes « - dies Wort sucht die Dimension der großen, von täglicher Einzelkriminalität verschiedenen Verbrechen in Worte zu fassen - systematisch zu ahnden, weil nur so das Regime von Grund auf in Form der Neukonstituierung einer humanen Rechtsordnung überwunden werden kann: »Im Zusammenhang mit dem Kriege sind zahlreiche Verletzungen des Rechts begangen worden. Sie sind nach Art, Ausmaß und Willensrichtung schwerwiegend und verabscheuenswert. Ihre Bestrafung ist nur zur Wiederaufrichtung der Herrschaft des Rechts und damit des Friedens in Deutschland und in der Völkergemeinschaft ein dringendes Gebot. "s Unter diesem Gesichtspunkt ist es konsequent, daß den technischen Entwürdigungs-, Diskriminierungs- und Tötungsermächtigungen des Regimes - von der Reichstagsbrandverordnung bis zur Polenstrafrechtsverordnung - keine Rechtsqualität zugemessen wird. Diese Regelungen sollen von Anbeginn außer Kraft gesetzt werden: „Es ist... die Schaffung einer rückwirkenden deutschen Strafbestimmung nötig, welche im ordentlichen Strafrechtszuge den Rechtsschänder mit Freiheitsstrafe oder Todesstrafe belegt. ... Bei einer auf Befehl begangenen Rechtsschändung ist der Befehl kein Strafausschließungsgrund, es sei denn, daß es sich um eine unmittelbare Bedrohung von Leib und Leben des Täters handelt oder ein sonstiger Zwang vorliegt ... Insbesondere ist der Befehl kein Strafausschließungsgrund, wenn der Täter durch sein Verhalten vor, bei oder nach der Tat erwiesen hat, daß er den Befehl billigt. ${ }^{6}$ (In einem späteren Entwurf hat van Husen seine Haltung verändert und die Außerkraftsetzung von NS-Recht auf eine deklaratorische Ebene zurückgenommen.) ${ }^{7}$

Die ursprüngliche Position van Husens findet ihre weitgehende Entsprechung in einem Intellektuellenkreis der Emigration, der Gruppe um Franz L. Neumann. Er war in der letzten Phase der Weimarer Demokratie Justitiar der SPD und publizierte in den USA die epochemachende Gesamtanalyse des NS-Systems, den »Behemoth ${ }^{8}$ Seit 1943 ist diese Gruppe in die Deutschlandplanung der amerikanischen Regierung einbezogen. Für sie hat die Ahndung der Staatsverbrechen den gleichen Stellenwert wie für den Kreisauer Kreis. Nachdem die Neumann-Gruppe die systematische Aufhebung von Rechtsschranken, die "gesetzlose Aktion der öffentlichen Behörden «, vor allem anhand der Schriften des Justitiars der SS, Werner Best, als Herrschaftsprinzip des Regimes herausgearbeitet hat, kommt sie zu dem folgerichtigen Ergebnis, daß die Anwendung der von der überwiegenden Mehrheit der Völker anerkannten Grundregeln von Recht und Moral auf die Naziführer »nicht Rechtlosigkeit bedeutet, sondern das Einklagen von Gerechtigkeit «. ${ }^{9}$ Diese Erkenntnis führte zur Forderung der Außerkraftsetzung der Nazi-Gesetze von Beginn an - wie in dem einen Entwurf des Kreisauer Kreises. In der Begründung heißt es: »Interpretiert man die Nazi-Gesetze entsprechend der Nazi-Ideologie, so kann kein Mord in einem Konzentrationslager als Verbrechen gelten; denn es ist der Kern der Politik und Verfassungstheorie der Nazis, daß die Handlungen der Parteiorgane als souveräne Handlungen keiner gerichtlichen Überprüfung unterliegen. $\aleph^{10}$

5 Deutsche Betelligung an der Bestrafung von Schandtaten, in: G. van Roon, Neuordnung im Widerstand. Der Kreisauer Kreis innerhalb der deutschen Widerstandsbewegung, Dokumentenanhang, Munchen 1967, S. $553 \mathrm{f}$

6 Ebd., S. 554 .

7 Ebd., S. 557.

8 F. L. Neumann, Behemoth. Struktur und Praxis des Nationalsozialısmus (1942/44), Koln 1977.

9 A. Sollner (Hrsg.), Zur Archaologie der Demokratie in Deutschland. Analysen politischer Emigranten Im amerikanischen Geheımdıenst, Bd. I : 1943-1945, S. 168 f., S. 172.

10 Ebd., S. 185 . 
In der durch die alliierte Suprematie bestimmten Nachkriegsperiode wird die doppelte Zielsetzung der Verfolgung und Ahndung der größten Staatsverbrechen der deutschen Geschichte - die in ihrer Ungeheuerlichkeit selbst strafrechtlich kaum zureichend zu erfassen sind" - und der Qualifizierung des Widerstands als legalem Handeln (unabhängig von den juristischen Repressionsnormen des Regimes) rechtlich fixiert. Während im Kontrollratsgesetz Nr. Io vom Dezember 1945 insbesondere der Tatbestand der Verbrechen gegen die Menschlichkeit geschaffen wird, der die Diskriminierungs- und Terrornorm des Regimes - wie schon durch die Einzelgesetzgebung der Alliierten - von Anfang an außer Kraft setzt, ${ }^{12}$ so wird durch die von den Alliierten inspirierte Landesgesetzgebung den politischen Widerstandskämpfern ausdrücklich zuerkannt, daß ihr Handeln vollständig legal war. Das Gesetz zur Wiedergutmachung des nationalsozialistischen Unrechts in der Strafrechtspflege, das in der amerikanischen Zone 1946 erlassen wurde, stellt fest: »Politische Taten durch die dem Nationalsozialismus oder Militarismus Widerstand geleistet wurde, sind nicht strafbar. ${ }^{13}$ Diese Feststellung ist in einer Bemerkung von Eugen Rosenstock-Huessy, die die Machtrealität hinter sich läßt und die Begründung für den gesamten politischen Widerstand exemplarisch festhält, treffend konkretisiert worden: "James von Moltke und Dietrich Bonhoeffer waren im Augenblick ihrer Hinrichtung die legitime deutsche Staatsgewalt, und zwar die einzige. «'4

Die normativen Antworten auf eine schrankenlose Staatsgewalt, die von deutscher Seite bekanntlich Gustav Radbruch auf den Begriff des gesetzlichen Unrechts brachte, ${ }^{15}$ wurde vor allem im Nürnberger Prozeß und in den zwölf Nürnberger Nachfolgeprozessen der USA gegen die Funktionseliten des NS-Regimes - von den Einsatzgruppen über die Justizbürokratie bis zum Oberkommando der Wehrmacht - wirksam. In der Entscheidung zu den Einsatzgruppen vom i 8. 4. 1948, jener mit der Wehrmacht - aufgrund einer vor Beginn des Rußlandfeldzuges getroffenen Übereinkunft - kooperierenden Tötungskommandos, ${ }^{16}$ tritt der erzhumane Impuls der Urteile der amerikanischen Richter besonders deutlich zutage: »Hier sind Verbrechen, die infolge der Tiefe und Weite ihrer Verkehrtheit der Beschreibung trotzen. Hier erreicht die Erbarmungslosigkeit ihren Tiefpunkt, und nichts in Dantes imaginärem Inferno kann den Schreckenstaten gleichen, die sich, wie wir gefunden haben, in den Jahren 1941, 1942 und 1943 in Weißruthenien, der Ukraine, Litauen, Estland, Lettland und der Krim ereigneten. « ${ }^{17}$ An anderer Stelle des Urteils wird das Verhältnis von Opfer und Mörder so beschrieben: »Was erwarteten die Henker, das die Opfer sagen sollten? Wer hätte Worte finden können, um zu diesem unsäglichen Angriff auf die Menschlichkeit, dieser ungeheuren Vergewaltigung der Würde des Lebens und des Daseins etwas zu sagen? Sie schwiegen, hier gab es nichts mehr zu sagen. ${ }^{18}$

Einer der Verurteilten ist der SS-Führer Dr. Martin Sandberger, Leiter des Einsatz-

I I Vgl. H. Arendt, Brief vom 17.8. 1946 an Karl Jaspers, in: H. Arendt/K. Jaspers, Briefwechsel 1926-1969, Munchen 1985, S. $90 \mathrm{f}$.

12 Art. II Ziff. I c.

13 Zit. nach G. Radbruch, Gesetzliches Unrecht und ubergesetzliches Recht (1946), in: ders., Der Mensch im Recht, Gottingen I961, S. 121 .

14 Zit. nach G. van Roon, Helmut James von Moltke, in: Liebhaber des Frsedens, hrsg. v. H. J. Schultz, Stuttgart 1982, S. 200

15 G. Radbruch (Fn. 13)

I6 R. Hilberg, Die Vernichtung der europàischen Juden (1961), Bd. 2, Frankfurt/M. 1990, S. 298, S. 287 ff.;

H. Krausnick, Hitlers Einsatzgruppen (1981), Frankfurt/M. 1985.

17 Das Urteil im Einsatzgruppenprozeß, Berlın (Ost) 1963, S. I 34

18 Ebd., S. 67 . 
kommandos 1 a in Estland. Er ist für die Ermordung der Juden in diesem baltischen Land verantwortlich. Das amerikanische Gericht konstatiert: »Es ist ... (eine) Tatsache, daß für besondere Aktionen die estnische Miliz Sandbergers Zuständigkeit und Kontrolle unterstellt war. ${ }^{19}$ In einer offiziellen Ereignismeldung hieß es: „Die Festnahme aller männlichen Juden über 16 Jahre ist fast abgeschlossen. Mit Ausnahme der Ärzte und der vom Sonderkommando eingesetzten Judenältesten werden sie durch den estnischen Selbstschutz unter Kontrolle des Sonderkommandos r a exekutiert. $\ll^{20}$ Im Verhör erklärt Sandberger auf die Frage, ob er damals in Estland war: "Ja, aber sie (die Ermordeten) sind nicht unter meiner Verantwortung erschossen worden. Unter meiner Verantwortung waren es etwa $350 . \ll^{21}$

\section{Ausböblung der Rechtspositionen der Regime-Gegner}

Mit Beginn der soer Jahre geraten die Positionen der Nachkriegsperiode - die Ahndung von Staatsverbrechen und die Anerkennung der Legalität des Widerstandes ins Wanken. Dies hängt mit zwei, sich verstärkenden Prozessen zusammen: der weitgehenden Inkorporation des Staats- und Justizapparats der NS-Diktatur und der Ausbildung und Zuspitzung des Kalten Krieges im Zuge der Wiederbewaffnung, durch den die plakativ antikommunistischen Ideologien modifiziert wieder erstehen konnten. ${ }^{22}$ Diese Ideologien fanden in der autoritären Realität des Staatssozialismus - trotz gewisser Ansätze eines demokratischen Marxismus unter Intellektuellen und der Arbeiterschaft - einen Anhalt. Die Funktion des regierungsamtlichen Antikommunismus bestand aber wesentlich darin, das außerhalb des stalinistischen Herrschaftsmodells angesiedelte Denken in Kategorien gesellschaftlicher und staatlicher Diskontinuität gegenüber dem Dritten Reich, das amerikanische Deutschlandplaner, Gruppen des politischen Widerstands, linke Christdemokraten und die Sozialdemokratie entwickelt hatten, ${ }^{23}$ zu blockieren.

Unter dem Druck der weitgehenden institutionellen und ideologischen Kontinuität nimmt die Distanz zu den Funktionseliten des NS-Regimes unterhalb der politischen Spitze ab. Es wurde gedanklich in einen tendenziell normalen Staat transformiert. Selbst der Hitlergruß enthielt für den Bundesdisziplinarhof von r955 einen rechtsstaatlichen Kern im Sinne der Achtung der legalen Autorität. Ohne Bedeutung sei es gewesen, dekretiert das Gericht, daß "die damals vorgeschriebene Form des Grußes die des Hitlergrußes war «. ${ }^{24}$

Es ist kein Zufall, daß in der frühen Bundesrepublik kein Gedenktag zur Installierung des Nazi-Regimes - etwa am 30. Januar - eingerichtet wurde. Arnold Brecht, bis 1933 Ministerialdirektor im preußischen Staatsministerium, später Professor in den Vereinigten Staaten, hatte angeregt, den 30. Januar jeden Jahres zum nationalen Bußtag zu erklären. ${ }^{25}$ Auch ein Gedenktag für den deutschen politischen Wider-

19 E.bd., S. 173 .

20 Ebd.

2 I Ebd., S. I74.

22 Zur Interpretation vgl. E. Kogon, Die Funktion des Antıkommunismus in der Bundesrepublik Deutschland, Frankfurter Hefte, H. 1/1970, S.80 ff.

23 A. Sollner (Fn.9), Manifest der demokratischen Sozialisten des ehemaligen Konzentrationslagers Buchenwald vom 13.4.1945, in: W. Abendroth, Aufstieg und Krise der deutschen Sozialdemokratie, Frankfurt/M. 1964, S. 1 23 ff.; A. R. L. Gurland, Die CDU/CSU. Ursprunge und Entwicklung bis 1953, Frankfurt/M. 1980; E. U. Huster, u.a., Determinanten der westdeutschen Restauration 1945-1949, Frankfurt/M. 1972, Dokumentenanhang, S. $363 \mathrm{ff}$.

24 BDHE 2, S. 178 f.; s. hierzu M. Kirn, Verfassungsumsturz oder Rechtskontınuitat?, Berlin 1972, S. 279 .

25 A. Brecht, in: H. Kesten (Hrsg.), Ich lebe nicht in der Bundesrepublik, Munchen 1963, S. 32. 
stand - etwa am 20. Juli - ist nicht eingeführt worden - ungeachtet der jährlichen

Feiern zur Wiederkehr des Tags des Attentats von Stauffenberg. Gedenktage signalisieren die Selbstfindung eines Gemeinwesens. Das Fehlen eines auf das NS-Regime gerichteten Gedenktages hat selber symbolische Bedeutung. Erst jetzt ist dieser Bann gebrochen - mit der auf Initiative von Ignatz Bubis getroffenen Entscheidung, des Tags der Befreiung von Auschwitz am 27. Januar zu gedenken.

\section{Weitgebende Straffreibeit für Staatsverbrechen}

Die Abwehr der Erinnerung entsprach der Tendenz zur Zurückdrängung der Ahndung von Staatsverbrechen. Für die an diesen Verbrechen beteiligten Täter setzt Anfang der soer Jahre, angeführt von der Bundesregierung und von Verteidigern der Nürnberger Prozesse, weitgehend gestützt durch die öffentliche Meinung und durch führende Repräsentanten der evangelischen und katholischen Kirche, eine Begnadigungskampagne ein. Das Ziel war, die überwiegende Mehrzah] der verurteilten NS-Täter - nicht zuletzt auch der der Nürnberger Nachfolgeprozesse - auf freien Fuß zu setzen. In schlechter Allgemeinheit wurden die Täter als »Kriegsverbrecher «, manchmal lediglich als "Kriegsverurteilte akte mit Kriegshandlungen nicht das Geringste zu tun hatten. Der Sinn der Kampagne steckt im Wort "Amnestie «; es heißt: vergessen. ${ }^{26}$

Welche Verankerung die Forderung nach Begnadigung von NS-Mordtätern in den Spitzen der jungen Bundesrepublik selbst bei dezidiert antinazistischen Politikern, Kirchenleuten, Professoren, besaß, zeigt der Fall Sandberger. Seine Verurteilung wegen Einsatzgruppenverbrechen ist schon erwähnt worden. Für die Begnadigung Sandbergers, der ja vor Gericht zugegeben hatte, 350 Menschen getötet zu haben, setzten sich der evangelische Landesbischof von Württemberg, Haug, das FDPVorstandsmitglied Mayer, der Vizepräsident des deutschen Bundestages, Carlo Schmid, und am Ende auch Bundespräsident Heuss ein. ${ }^{27}$ Carlo Schmid, der 1955 in seiner Rede zur Woche der Brüderlichkeit in der Frankfurter Paulskirche so treffend davon sprach, daß »den Opfern der Rang des Menschen aberkannt ${ }^{28}$ wurde, intervenierte zwei Jahre zuvor zugunsten von Sandberger: Er wolle und könne, »heute so wenig wie anläßlich meiner einstigen Bemühungen um gnadenweise Umwandlung der ursprünglichen Todesstrafe in eine lebenslängliche Freiheitsstrafe, die Gerechtigkeit der Verurteilung Sandbergers in Frage stellen «. Carlo Schmid aber erklärte, daß »dieser Mann kein blindwütiger Fanatiker gewesen sein kann «. ... » Er war ein fleiBiger, intelligenter und begabter Jurist, der auf der einen Seite dem geistigen Nihilismus der Zeit verfallen war, auf der anderen Seite aber sich krampfhaft an der Formenwelt der Bürgerlichkeit festklammerte ... Man sollte Martin Sandberger eine Chance geben, sich im Leben neu (!) zu bewähren. « ${ }^{29}$ Was Carlo Schmid, ohne wohl das Urteil gegen Sandberger zu kennen, als seine positiven, von seinem Handeln als Einsatzgruppentäter abtrennbaren Eigenschaften heraushebt, sind gerade jene Cha-

26 In diesem gesellschaftıchen Klima wurde die Regelung, im „Gesetz zur Versorgung der Opfer des Krieges", geschaffen, daß auch NS-Tater Anspruch auf Kriegsopferrenten haben. Die Ausschlußregelung, daß Kriegsverbrecher keinen derartigen Anspruch besitzen sollten, wurde nach einer Intervention des FDP-Abgeordneten Mende, der gegen eine sogenannte "Prolongierung der Entnazifizierung " Front machte, gestrichen. T. Kleine-Brockhoff, Zuschlag fur die Tàter, Die Zeıt v. 3 r. I. 1997. Vgl. insgesamt N. Frei, Vergangenheitspohtık. Die Anfange der Bundesrepublik und die NS-Verbrechen, Munchen 1996, S. ${ }_{33}$ ff.

27 N. Freı (Fn. 26), S. $299 \mathrm{ff}$

28 C. Schmid, Zur Woche der Bruderhichkeit (1955), in: ders., Politik und Geist, Munchen 1964, S. 84. 29 N. Fre1 (Fn. 26), S. 3 co. 
raktermerkmale, die von einem kühlen Einsatzgruppenkommandeur verlangt wurden. ${ }^{3 \circ}$ In der Personalbeurteilung Sandbergers durch die SS heißt es: "Sehr großer Fleiß und überdurchschnittliche Arbeitsintensität zeichnen ihn ... aus. In fachlicher Hinsicht hat sich Sandberger sowohl im Reichs- wie auch im sicherheitspolizeilichen Osteinsatz bewährt. « ${ }^{31}$ Theodor Heuss, der 1952 in Bergen-Belsen die »Pedanterie des Mordens als schier automatischen Vorgang ohne das bescheidene Bedürfnis nach

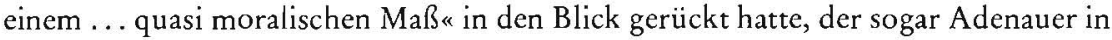
einem Gespräch nahe legte, seinen Staatssekretär Globke wegen der Vorwürfe gegen ihn gegebenenfalls Konsequenzen ziehen zu lassen, ${ }^{32}$ schaltete sich nach längerem Zögern zugunsten von Sandberger ein: Die Gnade sei, schrieb Heuss 1955, als »schönste(r) Teil« »dem Recht beigeordnet «., ${ }^{33} \mathrm{Ob}$ Gnade, die ohne privilegierende Intervention gewiß ihre Rechtfertigung besitzt, für einen hundertfachen Mörder unschuldiger Menschen mit dem Begriff des Rechts, das die Ohnmächtigen schützt und die Bewahrung des Lebens einschließt, zusammengebracht werden kann - diese Frage beantwortet sich selbst.

In der unaufgelösten Spannung zwischen einer Wahrnehmung der Terror-Struktur des Regimes und einer fast gleichzeitigen Laxheit im Umgang mit der Rolle bestimmter Täter zeigt sich, selbst bei den großen liberalen und humanen Gründungsvätern unserer Republik, welche Tiefenwirkung das allgemeine gesellschaftliche Bewußtsein einer teilweisen Umwertung der Schuldfrage, deren Beantwortung Karl Jaspers schon 1946 als Basis eines Neubeginns ansah, ${ }^{34}$ hatte.

Die Intervention führender Repräsentanten der Bundesrepublik zugunsten der Begnadigung eines ranghohen Einsatzgruppentäters hat vielfältige, hier nur knapp zu benennende Ursachen. Das Vorgehen von Schmid und Heuss war keine Einzelaktion. Sie stand im Zusammenhang einer mächtigen gesellschaftlichen Tendenz. Eine wichtige Rolle spielte die Schichtzugehörigkeit des Täters. Im Unterschied zu anderen NS-Tätern, etwa KZ-Verbrechern, für die sich keine Gnadeninitiative von Honoratioren einsetzte, stammte der promovierte Jurist und SS-Führer Sandberger aus dem wohlhabenden württembergischen Bürgertum. ${ }^{35}$ Noch als Mörder im Staatsauftrag blieb er in bestimmtem Maße dessen Teil. Dies war möglich, weil Sandbergers Massentötungen für die Begründung des Gnadengesuchs von seiner Person separiert und damit nahezu entwirklicht wurden. Derart wurde die Identifikation mit seiner so "gereinigten « Person möglich - von Akademiker zu Akademiker. Sie findet ihre Grundlage in den bei Sandberger ausdrücklich hervorgehobenen Sekundärtugenden, die aus dem gemeinsamen bürgerlichen Moralkodex entspringen. Das Eintreten für den einst im Dienst des Reichssicherheitshauptamts tätigen Kommandeur des Sonderkommandos ra war für Schmid und Heuss umso leichter möglich, als dies nicht-öffentlich geschah. ${ }^{36}$ In der Öffentlichkeit wäre dies Vorgehen - trotz ähnlicher Positionen in liberalen und konservativen Blättern - kritisch thematisiert worden - von der Neuen Zeitung oder der Frankfurter Rundschau. ${ }^{37}$

Die allgemeine Begründung für eine Begnadigung, die mit einigen Verzögerungen

30 R. Hilberg (Fп. 16), S. 335.

3 I Das Urteil im Einsatzgruppenprozeß (Fn. 17), S. 176.

32 Th. Heuss, Das Mahnmal (1952), in: ders., Geist der Politik, Frankfurt/M. 1964, S. 4 ; Konrad Adenauer/Theodor Heuss, Unter vier Augen. Gesprache aus den Grunderjahren, bearb. v. H. P. Mensing, Berlin 1997, S. 197.

33 N. Frei (Fn. 26), S. 301.

34 K. Jaspers, Die Schuldfrage (1946), Munchen 1987; ähnlıch M. Niemoller, Der Weg ins Freie, Stuttgart 1946.

35 N. Frei (Fn. 26), S. 298.

36 Ebd., S. $299 \mathrm{ff}$.

37 Ebd., S. 189, S. 151, S. 214 , S. 233, S. 246f., S. 276; H.J. Doscher, Verschworene Gesellschaft. Das Auswartige Amt unter Adenauer zwischen Neubeginn und Kontınutat, Berlin 1995, S. is $5 \mathrm{ff}$. 
und Einschränkungen in bestimmten (wenn auch nicht im vollen) Maße etwa für leitende Funktionsträger des Auswärtigen Amtes, der Justizbürokratie, der Einsatzgruppenleiter von den Alliierten schließlich erfolgte, ${ }^{38}$ variierte unter den politischen Protagonisten. Konrad Adenauer und der der CDU angehörende Staatssekretär im Justizministerium, Walter Strauß, vertraten die These, daß unter den Kriegsverbrechern zwar ein gewisser Prozentsatz »richtiggehende Verbrecher ", die meist vorbestraft seien, festzustellen sei - Strauß bezifferte ihn auf 10 Prozent. ${ }^{39}$ Die überwiegende Mehrzahl der Verurteilten wurde jedoch als nicht $\mathrm{zu}$ Recht verurteilt angesehen. Diese Wertung von Strauß, die er von Anwälten der Nürnberger Verfahren übernahm, ${ }^{40}$ war einigermaßen willkürlich; sie gründete sich nicht auf eine detaillierte juristische Auseinandersetzung mit den Nürnberger Entscheidungen, die zudem - bis auf zwei Ausnahmen ${ }^{-41}$ nicht in westdeutschen Verlagen veröffentlicht wurden. Wenn man das Nürnberger Juristenurteil oder das Einsatzgruppenurteil liest, ${ }^{42}$ wirkt die Vorstellung, daß 90 Prozent der für Mordaktionen, Terrorurteile und Ausmerzungsnormen Verantwortlichen zu Unrecht verurteilt wurden, wie ein amtliches Augenschließen vor dem einstigen staatlichen Schrecken.

Die Argumentation Adenauers unterschied sich von einer radikaleren Position, mit der für eine Generalamnestie für alle Staatsverbrecher plädiert wurde. Diese Position wurde von dem schon erwähnten ehemaligen Justitiar der SS, Werner Best, einst Stellvertreter Heydrichs im Reichssicherheitshauptamt, 1952 systematisch und nachhaltig wirksam entwickelt. ${ }^{43}$ Best war in der Bundesrepublik kein Außenseiter. Er war eine wichtige Figur im nationalistischen Flügel der FDP. Er arbeitete bald nach seiner Rückkehr aus dänischer Gefangenschaft seit Beginn der soer Jahre in der Anwaltskanzlei des FDP-Abgeordneten Achenbach und besaß gute Verbindungen zum Justizministerium. ${ }^{44}$ Best hatte im NS-Regime den juristischen Herrschaftsmechanismus entwickelt, mit dem rechtliche Schranken nach politischer Opportunität gegenüber Juden, politischen Oppositionellen und anderen Gruppen nach Belieben durchbrochen werden konnten. Seine einstige, den Staatsterror rechtstechnisch legitimierende Grundposition behielt Best unter veränderten politischen Umständen einer rechtsstaatlich demokratischen Ordnung bei: In einer Denkschrift unter dem bezeichnenden, scheinsachlichen Titel »Gesichtspunkte zur Liquidation politischer Strafsachen einer abgeschlossenen Epoche« vertrat er, auch zur Selbstverteidigung, in scharfer Frontstellung gegen die sogenannte »nachtragende Unversöhnlichkeit der Alliierten « die Auffassung, daß kriminelle Akte - sogenannte politische Straftaten -, "die durch das Fehlen privater Motive und egoistischer Zwecke" charakterisiert seien, "vom gemeinen Verbrechen unterschieden seien «. ${ }^{45}$ Da eine Wiederholung ausgeschlossen sei, bestehe kein Strafbedürfnis. Eine Bestrafung sei »unvernünftig und unsittlich.$^{46}$ Diese Position von Best, die das durch und durch ideologische Selbstbild der NS-Täter reproduziert, die lediglich einen völkischen politischen Plan

38 A. Ruckerl, NS-Verbrechen vor Gerıcht, Karlsruhe 1982, S. 131; K. Bàstleın, Der Nurnberger Juristenprozeß und seine Rezeption in Deutschland, in: L. M. Peschel-Gutzeit (Hrsg.), Das Nurnberger Juristenurteil von 1947, Baden-Baden 1996, S. 29 ff.; H. Ostendorf/H. ter Veen, Das »Nuirnberger Juristenurteil «. Eine kommentierte Dokumentation, Frankfurt/M. 1985 , S. $32 \mathrm{f}$

39 N. Frei (Fn. 26), S. 271 ; U. Herbert, Best. Bıographische Studien uber Radikalismus, Weltanschauung und Vernunft, Bonn 1996, S. 456.

40 N.Frei (Fn. 26), S. 271.

41 Der Wilhelmstraßenprozeß, Schwabisch Gmund 1950; Das Urteil im IG-Farbenprozeß, Offenbach 1948 .

42 Vgl. J. Perels, Verpaßte Chancen. Zur Bedeutung der Nurnberger Nachfolgeprozesse, Beitrage zur Geschichte der nationalsozialistischen Verfolgung in Norddeutschland H. 3/1997.

43 U. Herbert (Fn. 39), S. 454 ff.

44 Ebd., N. Frei (Fn. 26), S. 106, S. I 14 f.

45 U. Herbert (Fn. 39), S. 458 . Zu Bests NS-»Rechts«-Position s. ebd., S. 163 ff., S. 196 ff., S. 275 ff.

46 Ebd. 
kühl vollstreckt hätten, ${ }^{47}$ dient der Legitimation zur vollständigen Abtrennung des Staatsapparats von rechtsstaatlichen Bindungen. Best wußte, wovon er sprach. Er hatte in Bayern die Röhm-Morde von 1934 organisiert, er führte später die Aufsicht über die Konzentrationslager, er organisierte die ersten Einsatzgruppen im Polenfeldzug, er entwarf in einem 1942 in der "Zeitschrift für Politik " erschienenen Artikel in aller Öffentlichkeit das Programm der »Vernichtung und Verdrängung fremden Volkstums « $4^{8}$

Das von Best entwickelte Exkulpationsschema zugunsten sogenannter altruistischer Staatsverbrecher hatte - auch wenn das Ziel einer Generalamnestie nicht erreicht wurde - für die Argumentation gegenüber den Alliierten eine gewisse Bedeutung. Für die überwiegend akademischen Täter konnte ihre Charakterisierung als nicht gewöhnliche Kriminelle eingesetzt werden.49

Wichtig wurden Bests Argumentationsfiguren auch für die innere Entwicklung der Bundesrepublik. Sie trugen zur Blockierung der juristischen Aufarbeitung von NSVerbrechen bei. In einem von Best entworfenen Schreiben an Vizekanzler Blücher (FDP) vom 3. I I. 1952 wird die Forderung der Einstellung aller deutschen NSVerfahren mit den Kategorien der Exkulpationskonstruktion begründet, daß es sich nicht um Handlungen aus persönlichen Motiven oder zum eigenen Vorteil, sondern auf Befehl oder aus politischer Überzeugung handele. ${ }^{\circ}$ Ein gleiches Schreiben erhielt Bundesjustizminister Dehler (FDP). Ihm wurde nahegelegt, »die Länderjustizverwaltungen zum Kurztreten hinsichtlich der fraglichen Prozesse zu veranlassen «." Dieses Ansinnen eines Spitzenfunktionärs der SS führte für mehrere Jahre zum Erfolg. Der SPD-Abgeordnete Menzel, Mitglied des Parlamentarischen Rates, später Innenminister von Nordrhein-Westfalen, berichtete 1960 im Deutschen Bundestag von einer Darstellung des Vertreters des Justizministeriums über den Stand der Strafverfolgung von NS-Verbrechen im Rechtsausschuß. Aufgrund der damaligen Erörterungen (der Jahre 1950/52) über eine Generalamnestie für alle in der Hitlerzeit begangenen Verbrechen hätten die Länder »an eine Art Trend in der Öffentlichkeit geglaubt, auf die Verfolgung jener Delikte nicht mehr so viel Wert legen zu müssen‘. Sie hätten ... sauf eine systematische Durchforschung der Vorgänge verzichtet.«s2 Die Folgen sind in der Statistik ablesbar. Von 1952 bis 1957 nimmt die Verfolgung von NS-Gewaltverbrechern - mit Ausnahme von KZ-Verbrechen, für die die privilegierenden Kategorien des sogenannten persönlich-korrekten Staatskriminellen üblicherweise nicht zutreffen - drastisch ab. $\$ 3$

\footnotetext{
47 Ebd., S. 20 f., S. 225 ff., S. 238 ff., S. 240 ff.; R.H.lberg (Fn. 16 ), S. 335 , S. 34 S

$4^{8}$ U. Herbert (Fn. 39), S. 143 ff., S. 147 ff., S. 237 ff., ${ }^{C} 283$.

49 In einer Erklarung des Deutschen Bundestages v $\ldots$ n Februar 1952 wurden bewußt oder unbewußt Kategorien von Best aufgenommen. Gefordert wurde, $n$ daß die Deutschen, die unter der Beschuldigung des Kriegsverbrechens entweder von alliierten Gerıchten bereits verurteılt oder noch ohne Urteil festgehalten sind, freigelassen werden, soweıt es sich nıcht um von den einzelnen zu verantwortende Verbrechen $1 \mathrm{~m}$ hergebrachten Sinne des Wortes handelt « (ebd., S. 455 ).

so Ebd., S. 460.

$s 1$ Ebd.

52 Verhandiungen des Deutschen Bundestages, 3. Wahlperıode, Stenographische Berichte, Bd. 46, Bonn 1960, S. 6682; s. hierzu F. Kruse, NS-Prozesse und Restauration, KJ H. 2/1978, S. 1 20 ff.

53 Ebd., S. 126.
} 
Parallel zur Amnestie von Kriegsverbrechern und Verbrechern gegen die Menschlichkeit und der vielfachen Blockierung der Verfolgung von NS-Verbrechen in der zweiten Hälfte der fünfziger Jahre wird der politische Widerstand gegen das Dritte Reich - bis auf die Wiedergutmachungsgesetzgebung - rechtlich überwiegend anders bewertet.

Hierfür sind wesentlich zwei Grundentscheidungen, die die Rechtspositionen des Widerstands, der Emigration und der Nachkriegsperiode zurückdrängen, maßgebend. Als Reaktion auf rechtsradikale Aktivitäten legte die SPD-Fraktion $1950 \mathrm{im}$ Deutschen Bundestag einen Gesetzentwurf "Zur Wiedergutmachung nationalsozialistischen Unrechts in der Strafrechtspflege vor, der den Widerstand gegen die NS-Gewaltherrschaft ausdrücklich als rechtmäßiges Handeln qualifiziert und alle Strafurteile, die auf politisch oder rassisch diskriminierenden Gesetzen beruhen, für nichtig erklärt. ${ }^{54}$ Dieser Gesetzentwurf wurde von Justizminister Dehler als »Gefahr für das ganze Gefüge der Rechtsordnung "s5 verworfen. Diese Haltung der Bundesregierung war von bestürzender Paradoxie, die aber der Logik der Umdeutung des nationalsozialistischen Normensystems entsprach: Die Entlegitimierung der nationalsozialistischen Rechtsordnung galt als Gefahr für die liberal-demokratische Rechtsordnung.

Zwei Jahre später ging die Bundesregierung noch einen Schritt weiter. Nicht nur die gesetzliche Feststellung des rechtsstaatlich legalen Handelns der Widerstandskämpfer unterblieb, weil damit die politischen Urteile des rekonstruierten Justizapparats in Frage gestellt worden wären. Auch dem Schlüsselbegriff zur Aufarbeitung des nationalsozialistischen Justizterrors, dem schon erwähnten Begriff des "gesetzlichen Unrechts«, der der Sache nach in der Europäischen Menschenrechtskonvention seinen Niederschlag fand, wurde seine Geltungsbedeutung ausdrücklich entzogen. Art. 7 II der Europäischen Menschenrechtskonvention lautete: »Durch diesen Artikel (der das Rückwirkungsverbot enthielt) darf die Verurteilung oder Bestrafung einer Person nicht ausgeschlossen werden, die sich einer Handlung oder Unterlassung schuldig gemacht hat, welche im Zeitpunkt ihrer Begehung nach den allgemeinen, von den zivilisierten Völkern anerkannten Rechtsgrundsätzen strafbar war.« 1952 lehnte es die Bundesregierung - wiederum im Sinne des reetablierten Staatsapparats - ab, diesen Satz in unsere Rechtsordnung aufzunehmen. ${ }^{56}$ Er hätte es - wie schon das Kontrollratsgesetz Nr. 10 - möglich gemacht, in technisch-juristische Formen gekleidete Staatshandlungen der NS-Diktatur an rechtsstaatlichen Maßstäben zu messen und gegebenenfalls für strafbar zu erklären. Damit schloß sich die Bundesregierung der Position der Verteidiger in den Nürnberger Prozessen - mit denen sie in Amnestiefragen ohnehin kooperierte - an und erklärte Akte der NS-Diktatur, sofern sie auf das nationalsozialistische Rechtssystem gestützt wurden, programmatisch für strafrechtlich irrelevant.

54 N. Frei (Fn. 26), S. 319.

is Ebd., S. 320 .

56 Bekanntgabe uber das Inkrafttreten der Konvention zum Schutz der Menschenrechte und Grundfreiheiten, BGBl., I954, II, S. 14 , 1. Ziff. 1 . 
Die Legitimierung des NS-Rechtssystems galt allerdings nicht absolut. Die Infragestellung der rechtlichen Legitimität des Widerstands wurde durch die nach vielen Auseinandersetzungen geschaffene Wiedergutmachungsgesetzgebung von 1956 in bestimmter Beziehung durchbrochen. Möglicherweise auch beeinflußt durch Theodor Heuss' große Rede vom "Recht auf Widerstand " von 1954, die freilich den Soldaten auch nach dem 20. Juli 1944 zuerkannte, »Deutschland vor dem Äußersten « - offenbar der Niederlage Nazi-Deutschlands - zu bewahren, ${ }^{57}$ enthält die Präambel des Bundesentschädigungsgesetzes der Sache nach den Begriff des gesetzlichen Unrechts; mit der Folge, daß Opfer und Angehörige von Opfern des NS-Regimes, auch und gerade wenn sie mit technisch-juristischen Instrumentarien der Diktatur verfolgt wurden, Entschädigungsansprüche geltend machen konnten. Ausdrücklich heißt es in $\$ 2$ II des Bundesentschädigungsgesetzes: "Der Annahme nationalsozialistischer Gewaltmaßnahmen steht nicht entgegen, daß sie auf gesetzlichen Vorschriften beruht haben oder in mißbräuchlicher Anwendung gesetzlicher Vorschriften gegen den Verfolgten gerichtet worden sind.«

Die Summe der Entschädigungszahlungen nach dem Bundesentschädigungsgesetz ist hoch, sie beträgt nach einer Statistik von 199494 Milliarden Mark. ${ }^{88}$ Ungeachtet dessen setzte sich unter den Bedingungen des Kalten Krieges selbst in der Entschädigungsgesetzgebung, in der ohnehin viele Opfergruppen wie Zwangssterilisierte, Zwangsarbeiter und Homosexuelle nicht berücksichtigt wurden, 59 eine normative Ausgrenzung des politischen Widerstands von Kommunisten durch, die ja zum Teil auch mit Männern des 20. Juli kooperiert hatten. ${ }^{60}$ Anders als in der Nachkriegsperiode, in der die späteren politischen Ziele der Oppositionellen als Anknüpfungspunkt nicht in Frage kam, ${ }^{61}$ besaß von 1956 an ein Kommunist, nach dem Verbot der KPD, sofern er die freiheitlich-demokratische Grundordnung bekämpfte, keinen Entschädigungsanspruch. ${ }^{62}$ Das aber hieß, daß Widerstand von Kommunisten im Dritten Reich - im Unterschied zu anderen politischen Kräften - keine Grundlage für eine Entschädigung bildete. Repressionshandlungen des NS-Regimes gegenüber Kommunisten wurden insoweit rechtlich nicht mehr hinterfragt, wie es ein Lüneburger Staatsanwalt in einem Staatsschutzverfahren tat, als er einem Kommunisten in seinem Plädoyer vorhielt, daß er schon im Dritten Reich wegen Wehrkraftzersetzung zweimal verurteilt worden war. ${ }^{63}$

\section{Verwandlung von Tätern in Gebilfen}

Sieht man von der Entschädigungsgesetzgebung und ihrer, allerdings zum Teil restriktiven Interpretation ab, zeigt sich in der Justiz ein überwiegend problematischer Umgang mit NS-Gewaltakten.

Die Rechtsprechung wird durch wesentlich zwei Argumentationsfiguren bestimmt,

57 Th. Heuss, Vom Recht zum Widerstand. Gedenkrede zum 20. Juli 1944, in: ders., Geist der Polıtik (Fn. 32), S. 47.

$58 \mathrm{~K}$. Brozik, Einmal und voller Lucken. Entschadigung und Ruckerstattung, in: Tater, Opfer, Folgen, Bonn 1995, S. 188.

59 Ch. Pross, Wiedergutmachung, Frankfurt/M. 1988, S. 103.

60 D. Beck, Julius Leber. Sozialdemokrat zwischen Reform und Widerstand, Berlın 1983, S. I95 If.

6I W. R. Beyer, Vom Ende der Wiedergutmachung, Demokratie und Recht, H. $3 / 1980$, S. 276.

62 A.v. Brunneck, Politische Justiz gegen Kommunisten in der Bundesrepublik Deutschland, Frankfurt/M. 1978, S. 296 ff.

63 Ebd., S. 230. 
die die sachgerechte juristische, aber auch historische Wahrnehmung der Staatsverbrechen des Dritten Reiches zumindest beeinträchtigen. Zur Bestimmung der Verantwortlichkeit bei den Mordaktionen der Einsatzgruppen, bei der NS-»Euthanasie « und bei den KZ-Verbrechen wird in der Mehrzahl der Fälle die Rechtsfigur der Beihilfe eingesetzt. Die These von der Gehilfenstellung bedeutet, daß der Handelnde, selbst wenn er eigenhändig getötet hat und eine umfassende Kommandogewalt besaß, die Tat nicht als eigene gewollt habe. ${ }^{64}$ Die Täterschaft wurde so in der Spitze des Regimes bei Himmler, Hitler und Heydrich angesiedelt, ${ }^{6 s}$ die ja alle nicht mehr lebten. In den amerikanischen und deutschen Entscheidungen zu NS-Gewaltverbrechen vor der Gründung der Bundesrepublik zeigte sich noch eine umgekehrte Tendenz. Die für Morde Verantwortlichen wurden fast ausschließlich als mit dem Regime identifizierte Täter angesehen. ${ }^{66}$

Für die Bundesrepublik ergibt eine Statistik des Bundesjustizministeriums vom 3r. Dezember I993 für die Zeit von 1948 bis I 993 folgendes Bild: Bis Ende 1993 wurden gegen 105688 Personen Ermittlungsverfahren wegen NS-Verbrechen eingeleitet. Rechtskräftig verurteilt wurden 6494 Angeklagte. Nur in 178 Fällen wurden NS-Verbrecher zu Höchststrafen verurteilt - zu Todesstrafe (bis 1949 zwölf Mal) und zu lebenslänglicher Haft (I66 Mal). Für den gleichen Zeitraum betrug das Verhältnis von Täterschaft und Beihilfe bei Einsatzgruppen $\mathrm{I}: \mathrm{I} 0$, bei Morden in Vernichtungslagern $\mathrm{I}: 3$ und bei KZ-Morden $\mathrm{I}: 2 .{ }^{67}$

Was diese Statistiken im einzelnen bedeuten, können nur umfassende Urteilsanalysen zeigen. ${ }^{68}$ Ein kurzer Blick auf typische Entscheidungen, bei denen überzeugte Karriere-Nationalsozialisten, die leitende SS-Ränge innehatten, als Gehilfen in einem ihnen äußeren, fremden Geschehen eingruppiert wurden, muß an dieser Stelle genügen. Der Führer des Einsatzkommandos 8, Dr. Otto Bradfisch, den das Gericht als »Anhänger der NS-Weltanschauung « bezeichnete, war für den Mord an 15000 Menschen auch durch eigene Tötungshandlungen verantwortlich. ${ }^{69}$ Das Schwurgericht des Landgerichts München I verurteilte den SS-Führer am 21.7. 1961 nicht als Täter, sondern als Gehilfen, und vermied es dabei, die auch bei Beihilfe mögliche Höchststrafe von lebenslangem Zuchthaus zu verhängen. Es hieß, daß es an Anhaltspunkten für eine eigene feindselige Einstellung von Bradfisch zur Judenfrage fehle $-7^{\circ}$ die organisatorische und praktische Lenkung der Ermordung von is 000 Juden durch einen SS-Führer hat, in einem objektiven Zynismus, für das Gericht mit einer feindseligen Einstellung gegen die Juden nichts zu tun..$^{71}$

Wie die Mehrzahl der Einsatzgruppentäter wurden auch leitende Funktionäre der NS-»Euthanasieaktion «, Reinhold Vorberg und Dietrich Allers, die nach Feststel-

64 Vgl. B. Nehmer, Die Tater als Gehilfen? Zur Ahndung von Einsatzgruppenverbrechen, in: Redaktion Kritische Justiz (Hrsg.), Die juristische Aufarbeitung des Unrechts-Staats, Baden-Baden 1997 (im Erscheınen); J. Baumann, Die strafrechtliche Problematık der natıonalsozıalıstischen Gewaltverbrechen, in: R. Henkys, Die nationalsozialistischen Gewaltverbrechen. Geschichte und Gericht, Stuttgart 1964, S. 267 ff.; C. Roxin, Straftaten im Rahmen organisatorischer Machtapparate, Goltdamer Archiv I963, S. $193 \mathrm{ff}$.

65 B. Nehmer (Fn. 64).

66 S. Benzler/J. Perels, Justiz und Staatsverbrechen. Über den jurıstischen Umgang mit der NS-»Euthanasie", in: H. Loewy/B. Winter (Hrsg.), NS-»Euthanasie" vor Gerıcht, Frankfurt/M. t996, S. 2 I f., S. 25 ; J. Perels (Fn. 42).

67 St. Wittke, Terlexkulpation von KZ-Tàtern?, in: Redaktion Kritısche Justiz (Hrsg.), Dic juristische Aufarbeitung des Unrechts-Staats (Fn. 64), m.w.Nachw.; B. Nehmer (Fn. 64).

68 Vgl. Redaktion Kritische Justız (Hg.), Die Aufarbeitung des Unrechts-Staats (Fn. 64).

69 F. Kruse, Zweierlei Maß fur NS-Tàter?, KJ H. 3/1978, S. 251 m.w.Nachw.

70 Ebd.

71 H. Arendt bemerkte: "Eine so finstere Figur wie Dr. Otto Bradfisch ... erklärte... 196I vor einem Münchner Gericht, er sei sinnerlich، stets dagegen gewesen. Offenbar brauchte er den Tod von is 000 Menschen, um sich außerlich ein Alibı in den Augen der wırklichen Nazis zu verschaffen. $\mathrm{H}$. A rendt, Eichmann in Jerusalem. Ein Bericht von der Banalitat des Bosen, Munchen 1964, S. 164. 
lungen des Gerichts eigene Vorstellungen zur besseren Tarnung der Krankentötungen entwickelt hatten, ${ }^{72}$ in einem Urteil des Landgerichts Frankfurt vom 20. 1 2. 1968 ebenfalls als Gehilfen, die nur den Willen der Staatsführung realisiert hätten, vorgestellt. Sie wurden wegen Beihilfe zu Mord zu Freiheitsstrafen von sieben und zehn Jahren verurteilt. Auch hier hieß es, »daß sich nicht feststellen ließ, daß sie gegenüber den Opfern feindselig gesonnen gewesen wären ${ }^{73}$ Die administrative Vorbereitung und Durchführung der Tötung hilfloser und unschuldiger Menschen hat in dieser teilexkulpierenden Umdeutung nichts mit einer feindseligen Einstellung zu tun - als ob die Tötung der psychisch Kranken nicht die äußerste Form der Feindseligkeit war. Zwischen den Morden und den wirklichen Tätern wurde eine Wand errichtet, die das wirkliche Geschehen weitgehend unsichtbar machte. Die - nur von einem geringen Teil der Justiz nicht mitgetragene - Tendenz der Verdrängung der aktiven und überzeugten Teilnahme an den Verbrechen des Regimes ist von führenden Strafrechtlern - von Jürgen Baumann, Fritz Bauer, Claus Roxin und Herbert Jäger - in einer Stellungnahme vor dem Deutschen Juristentag im Jahre 1966 eingehend kritisiert worden, ohne daß sich dadurch eine wesentliche Änderung der Judikatur ergab. In der Stellungnahme, der eine ähnliche des Rates der EKD vorausging, ${ }^{74}$ hieß es: "Die Kommission hat mit Besorgnis von Urteilen Kenntnis genommen, in denen NS-Gewaltverbrechen nach den in den Urteilen getroffenen Feststellungen mit auffallend niedrigen Strafen geahndet worden sind. In einem wesentlichen Teil dieser Fälle beruht das darauf, daß Täter des Mordes als Gehilfen verurteilt worden sind. «75 In der Haltung der Justiz verkörperte sich exemplarisch die weitgehende Abwehr der Wahrnehmung der Täterrolle in der Nachkriegsgesellschaft.

\section{Widerstand zwischen Ausgrenzung und Anerkennung}

Der Privilegierung von Tätern durch ihre Verwandlung in Gehilfen stand die vielfache rechtliche Entwertung des Widerstands durch die Justiz gegenüber. Allerdings folgte die Justiz keinem einheitlichen Interpretationsrahmen. Auf der einen Seite wurde der Widerstand, ganz im Sinne der Rechtspositionen der Nachkriegsperiode, durch die Justiz ausdrücklich rechtlich legitimiert, auf der anderen Seite aber wurde, und dies war in der Judikatur des Bundesgerichtshofs die vorherrschende Tendenz, der Widerstand durch die Exkulpation der NS-Justiz juristisch ins Unrecht gesetzt.

Für die eine Tendenz stand ein Verfahren von 1952: Das vom Braunschweigischen Generalstaatsanwalt Fritz Bauer - der bedeutendste juristische Kopf der Bundesrepublik in Sachen der Aufarbeitung der Untaten des Hitler-Regimes - 1952 vor dem Landgericht Braunschweig in Gang gesetzte Verfahren gegen den zweiten Vorsitzenden der Sozialistischen Reichspartei, Major Remer, der die Widerstandskämpfer des 20. Juli als Landes- und zum Teil auch als Hochverräter verunglimpft hatte, bot die Gelegenheit, das Recht auf Widerstand in aller Öffentlichkeit zu begründen und durch die Justiz bestätigen zu lassen. Die Konstellation war, auch wenn die Haltung der Bevölkerung zum Widerstand von vielen Vorbehalten gekennzeichnet war, gün-

72 S. Benzler, Justiz und Anstaltsmord nach 1945 , KJ H. 2/1988, S. 155 m.w.Nachw.

73 Ebd.

74 Wort des Rates der EKD zu den NS-Verbrecherprozessen vom 13.3.1963, in: R. Henkys, Die nationalsozıaliscischen Gewaltverbrechen (Fn. 63), S. $339 \mathrm{ff}$.

75 B. Just-Dahlmann/H. Just, Die Gehilfen. NS-Verbrechen und die Justiz nach 1945, Konigstein 1988, S. $263 \mathrm{~m}$.w.Nachw. In der Wiedergabe der Stellungnahme (ebd.) hat sich ein sinnentstellender Druckfehler enngeschlichen. Im folgenden, hier nicht wiedergegebenen Satz muß das Wort "viellescht" durch "vielfach « ersetzt werden. 
stig. Von Innenminister Lehr (CDU), der zum Goerdeler-Kreis gehört hatte, Angehörigen des Widerstands, bis zum ehemaligen Emigranten und Sozialdemokraten Fritz Bauer, bestand Einigkeit darin, der rechtsradikalen Diffamierung der politischen Opposition gegen Hitler entgegenzutreten. ${ }^{76}$

In einer Zeit, in der die rechtsradikale Ächtung des Widerstands in der Justiz nicht mehr in Zweifel gezogen wurde - das erste Urteil des Landgerichts München von 1951 sprach beispielsweise den Ankläger im Scheinverfahren gegen Canaris, Oster, Bonhoeffer u. a. unter Bezugnahme auf die NS-Rechtsordnung bereits frei -77, hob Fritz Bauer den Prozeß auf eine prinzipielle Ebene. Er gewann renommierte Gutachter, die das Recht des Widerstands gegen eine tyrannische Staatsgewalt systematisch begründeten. Besonderes Gewicht hatten zwei theologische Gutachter, die der in ihren Kirchen überwiegenden Fixierung auf die Treue zu jedweder Obrigkeit die halb verschüttete Tradition des biblischen Denkens gegen eine Unterordnung unter das staatliche Tier aus dem Abgrund entgegenstellten. Während der katholische Moraltheologe Rupert Angermair das System staatlich organisierter Rechtlosigkeit als nicht hochverratsfähig bezeichnete, weil der Tyrann selber zum Verräter am Gemeinwohl wurde, arbeitete der evangelische Theologe Hans Joachim Iwand die in Vergessenheit geratenen Ansätze eines Widerstandsrechts, das sich gerade auch auf Luther stützt, heraus. ${ }^{78}$ In dem Augenblick, in dem die Herrschaft des Anomos, des gesetzlosen Menschen, etabliert ist, entsteht das Widerstandsrecht. Gegenüber dem im zweiten Thessalonicherbrief erwähnten gesetzlosen Menschen "haben alle Träger irgendwelcher Autorität die Pflicht, von ihrer Gewalt aus das Recht neu aufzurichten. «79 Mit Luther sagt Iwand: "Die Gegenwehr wider die Bluthunde kann nicht aufrührerisch sein. $\aleph^{80}$

Fritz Bauer, der in einem Stuttgarter Gymnasium Mitschüler von Graf Stauffenberg war, zieht in seinem Plädoyer die Summe aus den Gutachten. In der trockenen Sprache des Juristen heißt es: »Ein Unrechtsstaat, der täglich Zehntausende Morde begeht, berechtigt Jedermann zur Notwehr ... Jedermann war berechtigt, den bedrohten Juden oder den bedrohten Intelligenzschichten des Auslandes Nothilfe zu gewähren. Insoweit sind alle Widerstandshandlungen durch den $\$ 53$ StGB gedeckt. $\ll^{81}$

Das Gericht folgte weitgehend der Argumentation von Fritz Bauer; der Vorwurf des Hochverrats schien dem Gericht vom Sachverhalt her nicht geklärt. Das Landgericht wies aber den Vorwurf des Landesverrats gegenüber den Widerstandskämpfern zurück und verurteilte Remer wegen der Verunglimpfung des Andenkens Verstorbener und entzog, ganz im Sinne der unmittelbaren Nachkriegsgesetzgebung, der NSJudikatur ihre scheinlegale Stütze. ${ }^{82}$

Diese rechtsstaatliche Legitimation des Widerstands wurde von der höchstrichterlichen Rechtsprechung und der ihr folgenden untergerichtlichen Judikatur nicht aufgegriffen. Bis auf zwei Einzelentscheidungen des Bundesgerichtshofs von $1952^{8_{3}}$

\footnotetext{
76 20. Juli 1944, bearb. v. H. Royce, Geleitwort von R. Lehr, Bonn o. J. (1952), S. 121 ff.; R. Wassermann, Zur juristischen Bewertung des 20. Juli. Der Braunschweiger Remerprozeß als Meilenstein der Nachkriegsgeschichte, Recht und Politik, H. $2 / 1984$, S. $68 \mathrm{ff}$.

77 J. Perels, Die schrittweise Rechtfertıgung der NS-Justiz, an: P. Nahamowitz/St. Breuer (Hrsg.), Politik-Verfassung-Gesellschaft. O. Massing zum 60. Geburtstag, Baden-Baden 1995, S. 55 f. m.w.Nachw.

78 R. Angermair, Darf ein Tyrann getotet werden?; H. J. Iwand, Gott mehr gehorchen als den Menschen, in: 20. Jull 1944 (Fn. 76), S. 135 ff., S. 141 f.

79 H. J. Iwand, ebd., S. 142.

80 H. J. Iwand, ebd., S. 144; M. Luther, Warnung an seine lieben Deutschen (1531), Werke Bd. 4, hrsg. v. O. Clemen, Berlin i950, S. 201.

81 F. Bauer, Der Generalstaatsanwalt hat das Wort, in: 20. Juli 1944 (Fn. 76), S. 155 .

82 R. Wassermann (Fn. 76)

83 Ebd.; J. Perels (Fn. 77), S. 57 m.w. Nachw.
} 
wurde schon die Fragestellung verworfen, ob die nationalsozialistische Rechtsordnung nicht im Kern ein System gesetzlichen Unrechts ist, weil sie Menschen als Untermenschen behandelt und den Gleichheitssatz systematisch zerstörte. ${ }^{84}$ In mehreren Urteilen des Bundesgerichtshofs wurde der Widerstand rechtlich entlegitimiert. 1956 wurde der SS-Richter Thorbeck von der Beihilfe zum Mord an Dietrich Bonhoeffer, Admiral Canaris, Hans Oster und anderen Widerstandskämpfern mit Blick auf ein angebliches legales Selbstbehauptungsrecht des nationalsozialistischen Staates freigesprochen; ${ }^{85}$ ein anderes Mal wurde ebenfalls 1956 der SS-General Simon, der unter anderem das Urteil gegen den Bauern Hanselmann bestätigt hatte, der kurz vor Kriegsende Hitlerjungen die Panzerfäuste weggenommen hatte und wegen Wehrkraftzersetzung in den Tod geschickt wurde, mit der Begründung freigesprochen, »daß die Sinnlosigkeit einer Fortsetzung des Krieges auf deutscher Seite denkgesetzlich nicht die Feststellung ausschloß, daß Hanselmann durch seine Tat mindestens mit bedingtem Vorsatz den Wehrwillen des deutschen Volkes zu zersetzen suchte. ${ }^{86}$ In beiden Entscheidungen wurde die Frage nach einer Praktizierung gesetzlichen Unrechts durch die NS-Justiz gar nicht erst aufgeworfen. Schließlich verweigerte der Bundesgerichtshof 1960 einem sozialdemokratischen Kriegsdienstverweigerer die Anerkennung als Widerstandskämpfer, weil sein Handeln keine Aussicht auf Erfolg besessen habe. Seinen Anspruch auf Entschädigung nach dem Gesetz über die Wiedergutmachung verwarf der Bundesgerichtshof ${ }^{87}$

Im Rehse-Urteil des Landgerichts Berlin von 1968, in dem der Beisitzer Freislers für die Mitwirkung an über zweihundert Todesurteilen nicht zur Verantwortung gezogen, sondern freigesprochen wurde, kommt die juristische Negation des Widerstandskampfes für eine rechtsstaatliche Ordnung zu sich selbst. Ganz auf der Linie des Bundesgerichtshofs wurde zum Beispiel der 1944 hingerichtete katholische Pazifist Max Josef Metzger - in Annelore Lebers Band von 1954 »Das Gewissen steht auf « ist schon ein Porträt von ihm enthalten $-^{88}$ indirekt ein zweites Mal wegen seines Memorandums für eine neue deutsche Staatsordnung von 1942 ins Unrecht gesetzt und Oberreichsanwalt Lautz, der Ankläger der Männer des 20. Juli, als sog. sachlicher juristischer Interpret des NS-Rechts herausgestelltr. ${ }^{89}$ So wurde die Geltung des nationalsozialistischen Normensystems zur Exkulpation des führenden NS-Richters eingesetzt.

Ein halbes Menschenalter später - nachdem die personellen Träger der frühen bundesdeutschen Justiz nicht mehr im Amt sind - hat der Bundesgerichtshof am I6. I I. I995 die Straffreiheit für NS-Richter und deren rechtliche Ausgrenzung von Widerstandskämpfern grundsätzlich kritisiert. ${ }^{90}$ In einzelnen Entscheidungen des Landgerichts Berlin sind, in später Anknüpfung an die Gedankenwelt der ersten Nachkriegsperiode die Verurteilungen von Bonhoeffer, Metzger und Jägerstätter inzwischen aufgehoben bzw. ihre Aufhebung erneuert worden.9

\footnotetext{
84 G. Radbruch (Fn. 13), S. 120 .

85 BGH, in: C. F. Rüter, u. a. (Hrsg.), Justiz und NS-Verbrechen, Bd. XIII, Amsterdam 1975, S. 352.

$86 \mathrm{BGH}$, in: Friedrich, Freispruch fur die Nazi-Justtz, Rennbek 1983, S. 355 .

87 BGH NJW 1962, S. 195 f.

88 A. Leber (Hrsg.), Das Gewissen steht auf. In Zusammenarbeit mit W. Brandt und K. D. Bracher, Berlin 1954, S. 184 f.

89 J. Friedrich (Fn. 86), S. 469 f., S. 485 .

90 BGH NJ 1996 , S. 156.

91 Vgl. J. Perels, Spate Entlegitimierung der NS-Justiz, KJ H. 4/1996, S. 504 ff.
} 
In der Bundesrepublik bildete sich ein extrem widersprüchlicher Umgang mit dem Widerstand aus. Jedes Jahr finden Feiern aus Anlaß der Wiederkehr des 20. Juli 1944 statt. In vielen Reden kommt das Selbstverständnis des neuen, demokratischen Gemeinwesens zum Ausdruck, das in der Negation der grenzenlosen Diktatur seinen wesentlichen Sinn erfährt. Zugleich aber sprach die Justiz, die doch an die Grundrechte gebunden ist und nicht an die machttechnischen Normen des NS-Systems, in ihrer Mehrheit Widerstandskämpfern gegen das NS-Regime mindestens implizit die rechtliche Legitimation ab. Dieser zwischen den Polen der Verdrängung und der Erkenntnis der NS-Despotie angesiedelte Dualismus hat tiefe gesellschaftliche Gründe.

Ein Grund besteht darin, daß in der Gesellschaft der frühen Bundesrepublik das NS-Regime vielfach in einen traditionellen, von Verbrechen nur äußerlich berührten Staat umgedeutet wurde, gegenüber dem dann auch ein Recht auf Widerstand nicht angezeigt war. Dies war die Sicht des größten Teils der traditionellen Eliten. Es ist symptomatisch, daß die Betrachtung der Rolle der beamteten Führungsschichten als mitverantwortliche Träger der Diktatur im rechtswissenschaftlichen und politischen Spektrum der Bundesrepublik in keinster Weise mehrheitsfähig war. Das Bundesverfassungsgericht hatte sie - im scharfen Gegensatz zum Bundesgerichtshof, der den Staatsapparat des Nationalsozialismus von den politischen Zielen des Regimes künstlich abtrennte - in seinen Gestapo-Entscheidungen von I 953 und 1957 entwikkelt. Die Vertreter der Staatsrechtslehre standen bis auf ganz wenige Ausnahmen an der Seite des Bundesgerichtshofs und unterstuitzten die These der politisch wertneutralen Rolle der Beamtenschaft im Dritten Reich. ${ }^{92}$

Die Bewertung der Struktur des NS-Regimes durch die traditionellen Eliten konnte sich in weitem Maße auf Tendenzen in der Bevölkerung stützen. In einer differenzierten, auf über fünfzehnhundert Probanden gestützten empirischen Studie des Instituts für Sozialforschung vom Beginn der soer Jahre, die unter dem Titel »Gruppenexperiment « erschien, wurden untergründige Einstellungen - Franz Böhm prägte dafür in seinem Vorwort den Begriff der "nicht-öffentlichen Meinung « - mit Blick auf das NS-Regime und seine Aufarbeitung ermittelt..93 Dabei ergab sich, daß die Schuld für die begangenen Untaten überwiegend - wie in der späteren GehilfenRechtsprechung zugunsten von NS-Tätern - den obersten Führern zugeschoben wurde. Die politische Spitze des Regimes wurde von der Gesellschaft radikal abgetrennt. Quantitativ stellte sich dies so dar: 60\% nahmen eine ablehnende Einstellung zur Mitverantwortung an KZ- und Kriegsgreueln ein. Lediglich $21 \%$ äußerten sich zustimmend zu einer Mitverantwortung an den KZ- und Kriegsgreueln. ${ }^{94}$ Die mit diesen Meinungsäußerungen verbundene Konstellation bezeichnet in gewisser Beziehung auch das gesellschaftliche Kräfteverhältnis, aus der sich eine gravierende Konsequenz ergibt. Sie wird in der Frankfurter Studie so formuliert: „Das vorgelegte Material ermächtigt wohl zu dem Schluß, daß zwar die nationalsozialistische Ideologie als in sich einheitlich organisierter Denkzusammenhang nicht mehr existiert, da ihr insbesondere durch den Mißerfolg ihre stärkste integrierende Kraft entzogen war, daß aber zahlreiche Einzelelemente des faschistischen Denkens, herausgebrochen aus ihrem Zusammenhang und darum oft doppelt irrational, noch gegenwärtig sind ... «s $^{95}$ Theodor W. Adorno, der an der Ausarbeitung des »Grup-

92 M. Kirn (Fn. 24), S. 231 ff., S. 253 ff.

93 F. Pollock (Bearb.), Gruppenexperiment. Ein Studienbericht. Geleitwort F. Bohm, Frankfurt/M. 1955.

94 Ebd., S. is 4 f.

95 Ebd., S. 397. 
penexperiments« beteiligt war, übersetzt diese empirischen Befunde der Studie wenige Jahre später in den sozialpsychologischen Tatbestand, daß »insgeheim, unbewußt schwelend und darum besonders mächtig jene Identifikationen (mit dem Hitlerregime) gar nicht zerstört wurden, sondern fortbestehen «. ${ }^{96}$

Dies belegen auch Meinungsumfragen, nach denen die Zeit von 1933 bis 1939, also ein Hitler-System ohne Krieg, von über $40 \%$ der Bevölkerung nach wie vor affirmiert wurde. ${ }^{97}$ Alltägliche politische Entscheidungen stehen ebenfalls unter dem Bann halb-nazistischer Stimmungen in der Bevölkerung. Im Oktober 1957 erwähnt Konrad Adenauer im Gespräch mit Theodor Heuss den Fall ejnes SS-Mannes, der in Frankreich eine Fülle »schauerlicher Verbrechen« begangen habe. Nachdem Adenauer die Verbrechen in dieser Weise charakterisiert hatte, bemerkt er: $\gg$ Die Vollstreckung des Urteils werde... zwölf Jahre nach Kriegsende doch zu einer erheblichen Beunruhigung in Deutschland führen müssen. Er (Adenauer) müsse deshalb einen Urlaub in Frankreich unbedingt vermeiden. «98

\section{$X I$. Fortexistenz der Logik des Maßnahmenstaates}

Das Resümee schmerzt. Durch eine weitgehende, mehrjährige Unterbindung der Strafverfolgung von NS-Verbrechern, durch die juristische Legitimierung von Terrorurteilen gegen Widerstandskämpfer und durch die vorherrschende Tendenz, überzeugte nationalsozialistische Gewalttäter zu Gehilfen in einem ihnen fremden Geschehen zu machen, wirkt in der Bundesrepublik im bestimmten Maße der Mechanismus des »Maßnahmenstaates « (Fraenkel), der sämtliche Rechtsgarantien unter den Vorbehalt der politischen Verfolgungs- und Vernichtungsziele der Exekutive stellte, ${ }^{99}$ weiter. Durch eine erhebliche Ahndungsblockade von Straftaten des NSRegimes gegen das Leben wird die Aufhebung subjektiver Schutzrechte noch einmal vollzogen.

Die gerühmte Stabilität der frühen Bundesrepublik beruhte wesentlich darauf, daß die Ahndung von NS-Verbrechen oftmals nur halbherzig, zu Zeiten gar nicht erfolgte. Die Massenloyalität gegenüber der neuen Republik beruhte wesentlich auf der vielfältigen Praxis der Verdrängung der gerade vergangenen Wirklichkeit des nationalsozialistischen Schreckenssystems, für den verschiedene Gruppen der Ge-

96 T. W. Adorno, Was bedeutet: Aufarbeitung der Vergangenheıt (1959), in: ders., Eıngriffe, Frankfurt/M 1963, S. 135

97 J. Perels (Fn. 4), S. 74 m.w. Nachw. In einem Brief an H. Blucher aus Bonn v. 14. I2. I949 macht $H$. Arendt eine ahnlıche Beobachtung: $₫$ Die Deutschen leben von der Lebensluge ... Nicht wahr ist, daß es hier viele Nazis gibt. Sie sehnen sich halt nach Hitlern ohne Krieg zuruck." Hannah A rendt-Heinrich Blucher, Briefe 1936-1968, Munchen 1996, S. 175; vgl. auch H. Arendt, Besuch in Deutschland (1950), in: diess., Zur Zeit. Politische Essays, Berlin 1986, S. 43 ff.

98 Konrad Adenauer/Theodor Heuss (Fn. 32), S. 232

99 E. Fraenkel, Der Doppelstaat (1941), Frankfurt/M. 1974, insb. S. $26 \mathrm{ff}$. In sennem Vorwort zur deutschen Ausgabe dieses Buchs berichtet Fraenkel uber einen Kontakt seines Freundes Martin Gauger, Justitiar des Lutherischen Rates, zu Werner Best: „Als es Martin Gauger nach vielen Múhen gelungen war, bis zu Best vorzudringen, um die Freıgabe von beschlagnahmten Geldern der Bekennenden Kirche zu erreichen, nahm er die Gelegenheıt wahr, gleichsam im Plauderton Best die Theorie des Doppelstaats klarzumachen. $W_{1 r}$ haben es als makabre Bestatıgung unserer theoretıschen Bemuhungen angesehen, das in einem Beitrag zum Jahrbuch der Akademie fur Deutsches Recht، [1937, S. I 32 ff.] Best weitgehend Gedankengange entwickelt, die Gauger ihm dargelegt hatte. « (Ebd., S. 17) Daß sich diese Konstellation in gewisser Wesse fortsetzte und Best in der Lage war, den kritischen Zentralbegriff Fraenkels, den des Maßnahmenstaates, positiv zu wenden und als Exkulpationsinstrument für staatskriminelle NS-Tater einzusetzen, wirft ein besonderes Licht auf die soer Jahre. Zwar hat Fraenkel ihre Struktur nicht systematisch untersucht. Aber seine Beobachtungen waren endeutig: "Da... alles, was sich seit dem 30. Januar 1933 abgespielt hat, weitgehend tabu ist, da niemand bereit ist, das Hitler-Regime offentlich zu verteidigen, fuhlen nur allzu viele sich zu ihrer inneren Befrıedigung der Aufgabe enthoben, es zu kritisieren. « E. Fraenkel, Deutschland und die westlichen Demokratien, 7. Aufl., Stuttgart 1964, S. g J. 
sellschaft und des Staates, die in ihre Stellungen zurückkehrten, direkte, indirekte oder ideologische Verantwortung trugen. Es wirkt wie ein Menetekel, daß das von der Berliner Generalstaatsanwaltschaft zu Beginn der 6oer Jahre vorbereitete Verfahren gegen 300 Beschuldigte des Reichssicherheitshauptamts - des Lenkungszentrums für den Massenmord - vollständig im Sande verlief. ${ }^{100}$ Möglich ist - das können aber erst genauere Forschungen zeigen -, daß die Tendenz zur nur begrenzten Verfolgung von NS-Staatsverbrechen nicht im Gegensatz zur Mehrheitsstimmung in der Bevölkerung stand. Zu denken gibt, daß die Prozesse der Alliierten gegen die Spitzen und Funktionsträger des Regimes nach Umfragen zunächst breite Unterstützung fanden, die dann zu Beginn der joer Jahre in eine überwiegende Ablehnung umschlug. ${ }^{\text {I01 }}$ Dann aber wäre dies ein bisher kaum wahrgenommenes Exempel für das Auseinandertreten von rechtsstaatlichem Anspruch und Demokratie.

\section{Verdrängung der Ermordung der Juden}

Max Horkheimer, der große Organisator und philosophische Exponent der intellektuellen Emigration in den USA, in der frühen Bundesrepublik zwei Jahre Rektor der Universität Frankfurt, wegen der Äußerung von Judenhaß durch einen Kollegen schon 1956 zur vorzeitigen Emeritierung entschlossen, ${ }^{102}$ zog eine bittere Bilanz seiner Erfahrungen in den soer Jahren. Seine Aufgabe hatte er so bestimmt: "Wir jüdischen Intellektuellen, die dem Martertod unter Hitler entronnen sind, haben nur eine einzige Aufgabe, daran mitzuwirken, daß das Entsetzliche nicht wiederkehrt und nicht vergessen wird, die Einheit mit denen, die unter unsagbaren Qualen gestorben sind. ... Ihre Verzweiflung und ihre Sehnsucht auszudrücken, sind wir da. "103 Im Gegensatz zur Rechtfertigung des Schweigens gegenüber den einstigen, geistigen Exponenten der NS-Herrschaft, wie sie Hermann Lübbe als gelungene Integrationsleistung der jungen Bundesrepublik betrachtete, ${ }^{104}$ bezeichnete Horkheimer in verzweifelter, möglicherweise auch selbstkritischer Schärfe die moralischen Kosten der Verdrängung: »Daß er (der Jude)... da bleibt, nachdem er wahrnimmt, wie das Nachkriegsdeutschland auf den Leichenbergen bloß Geschäfte macht, politische und kommerzielle ..., wie die Obermörder ihre Pensionen verzehren und die Anstifter und Nutznießer aufs neue ihren Rebbach machen - daß er das sieht und nicht so aufschreit, daß man ihn gleich mundtot oder ganz tot macht, sondern dabei noch mittut, ist der letzten Verachtung wert. $\ll^{105}$

Horkheimers Erfahrung ist mit der Celans verwandt. In der Frankfurter Allgemeinen Zeitung vom 2. Mai 1964 spricht Hans-Egon Holthusen in einer Rezension Celans realitätsgenauem Wort von den "Mühlen des Todes", das er in dem Gedicht "Spät und Tief « verwendet, jeglichen Gehalt ab. Dies sei eine in "X-Beliebigkeiten schwelgende Genitivmetapher ${ }^{106}$ Eichmann selber hatte schon-Peter Szondi weist

100 U. Herbert (Fn. 39), S. 498 ff., S. 507 ff.; I. Muller, Furchtbare Juristen, Munchen 1987, S. 246 ff.

101 U. Herbert (Fn. 39), S. 438 ; N. Frei (Fn. 26), S. 136 Fn.7.

102 R. Wiggershaus, Die Frankfurter Schule, Munchen 1986, S. $\{21$.

103 M. Horkheimer, Notizen 1950-1969, hrsg. v. W. Brede, Frankfurt/M. 1974, S. 213

${ }_{10} \mathrm{H}$. Lubbe, Es ist nuchts vergessen, aber einiges ausgeheilt. Der Nationalsozialismus im Bewußtsein der Gegenwart, Frankfurter Allgemeine Zeitung v. 24. 1. 1983. Lubbe nennt dies »integrative(s) Verhalten zu braunen Biographieanteılen " (ebd.) - ohne auch nur einen Fall personeller Kontinuitat wie etwa den von Theodor Maunz, 1943 noch geistiger Adept Werner Bests, historisch konkret zu untersuchen. Vg!. Th. Maunz, Gestalt und Recht der Polizei, Hamburg 1943, S. 9. Vgl. zur Kritik H. Dubiel/G. Franken-

berg, Entsorgung der Vergangenhert, Die Zeit v. 18.3. 1983.

Ios M. Horkheimer (Fn. 103), S. 161 f.

106 P.Szondi, Briefe, hrsg. v. C. König, T. Sparr, Frankfurt/M. 1993, S. 163, Anm. 2. 
in einem Leserbrief darauf hin ${ }^{107}$ - von der "Mühle in Auschwitz « gesprochen, und der Film, den die amerikanische Besatzungsmacht nach Kriegsende in vielen Städten zeigte, trug den Titel: "Die Todesmühlen «. ${ }^{108}$ Er vergegenwärtigte das Grauen in den Konzentrationslagern in Bilddokumenten. Mit der Auflösung des Epochenworts von den »Mühlen des Todes « gelingt die Verdrängung.

Es ist an der Zeit, sich der Erkenntnisse der überwiegend mißlungenen Aufarbeitung des nationalsozialistischen Schreckenssystems in der jungen Bundesrepublik zu stellen. Die kritische Reflexion dieser großen Blockierung gehört zur Selbstfindung unserer rechtsstaatlichen Demokratie.

\section{Ralf Kleinjans}

\section{Straffälligkeit türkischer Staatsangehöriger in Deutschland}

\section{Rechtsfolgen in Deutschland und in der Türkei}

Straffällig gewordenen türkischen Staatsangehörigen kann bei Rückkehr in die Türkei aus vielen Gründen eine (erneute) strafrechtliche Verfolgung drohen.

Der deutsche Jurist ist mit den Folgen dieser Situation im Ausländerrecht, Asylrecht und als Strafrechtler konfrontiert.

Die türkischen Gesetze und noch mehr die Rechtspraxis sind weitgehend unbekannt, schon weil sie teilweise nur schwer zugänglich sind.

Bisher fehlt ein Werk, das den Zugang erleichtert.

In der vorliegenden Arbeit findet man erstmals einen unverzichtbaren Überblick über Regelung und Handhabung des türkischen internationalen Strafrechts und ihre Auswirkungen auf die deutsche Rechtspraxis.

1997, 208 S., brosch., 79,-DM, 577,- öS, 72,-sFr, ISBN 3-7890-4929-8

(Nomos Universitätsschriften - Recht, Bd. 262)

107 P.Szondi, Brief v. 13.5. 1964 an die Frankfurter Allgemeine Zeitung (Fn. 106), S. 162; vgl. auch den ausfuhrlichen Brief von Szondi an R. Michaelis von der FAZ, ebd., S. I6; ff. sowie den Brief von Szondi an R. Hirsch vom Insel Verlag, ebd., S. $171 \mathrm{ff}$.

108 Vgl. die Besprechung dieses Films: E. Kastner, Was in den Konzentrationslagern geschah (1946), in: ders., Kàstner für Erwachsene, Frankfurt/M. 1966, S. $473 \mathrm{ff}$. 